\section{Postharvest Performance of Poinsettia Plants Exposed to Low Light Levels, Low Temperatures, and Low Substrate Moisture}

\author{
Ben A. Bergmann ${ }^{1}$, John M. Dole, and Ingram McCall
}

ADDITIONAL INDEX WORDs. environmental stress, Euphorbia pulcherrima, postharvest handling, postproduction, potted flowers

SumMARY. Responses of 14 to 20 poinsettia (Euphorbia pulcherrima) cultivars were assessed following exposure to environmental stressors common in the crop's postproduction supply chain and consumer environment: low light levels, low temperatures, and low substrate moisture. As indicated by number of days to unacceptable appearance, 14 cultivars tolerated three low light levels $(10,20$, and $\left.40 \mu \mathrm{mol} \cdot \mathrm{m}^{-2} \cdot \mathrm{s}^{-1}\right)$ well, with all individuals of six of the cultivars exhibiting an acceptable appearance at 7 weeks when the experiment ended. An experiment with 20 cultivars showed them to be surprisingly tolerant of low temperatures for a short duration, with no differences found when averaging across cultivars among plants exposed to 2,5 , or $20^{\circ} \mathrm{C}$ for 2 days. However, all cultivars exposed to $5{ }^{\circ} \mathrm{C}$ for 10 days performed poorly. Cultivars differed markedly in response to low substrate moisture, with frequency of unacceptable plants before 4 weeks across all treatments ranging from $0 \%$ to $87 \%$ among the 14 cultivars tested. Across 17 cultivars, acceptable plant appearance was extended from 23 days for plants that were never irrigated after $10 \mathrm{~d}$ in sleeves to 32 days for plants that received a single irrigation at unsleeving and not thereafter. The low temperatures and low substrate moisture experiments were conducted in 2 years, and years differed significantly for nearly all dependent variables assessed. The significant interaction between year and cultivar for all observed variables in those two experiments indicates the importance of conducting experiments such as these over 2 years or more. Potted plants of many of the poinsettia cultivars tested proved to be highly tolerant in terms of low light levels, low temperatures, and low substrate moisture. Three cultivars appeared to be most tolerant in two of the three experiments: Prestige Red (low light levels and low temperatures), Titan Red (low temperatures and low substrate moisture), and Whitestar (low light levels and low substrate moisture). Three cultivars were most tolerant to all three sources of postproduction plant stress: Christmas Day Red, Early Mars Red, and Titan White.

$\mathrm{F}$ actors that influence postharvest performance of potted poinsettia plants include cultivar, methods used during crop production, and postproduction handling. Cultivars have been improved steadily for aesthetic appeal, desirable production traits, and improved performance in postharvest environments. Greenhouse management protocols have been refined not only to optimize plant growth but also to take into account the growing list of production factors that have been shown to influence postharvest quality and longevity in poinsettia. These factors include temperature (Dunn et al., 2011; Moe et al., 1992; Staby and

Department of Horticultural Science, North Carolina State University, Raleigh, NC 27695-7609

We thank Syngenta Flowers for financial support.

${ }^{1}$ Corresponding author. E-mail: bergmann@ncsu. edu.

https://doi.org/10.21273/HORTTECH04106-18
Kofranek, 1979), substrate (Jackson et al., 2008; Roude et al., 1991), growth regulator application (Bailey and Miller, 1991), light intensity and duration (Bailey and Miller, 1991; Islam et al., 2012; Moe et al., 1992), fertilization (Nell and Barrett, 1986; Stromme et al., 1994; ter Hell and Hendricks, 1995), and irrigation regimes (Nell and Barrett, 1986).

The effects of postharvest handling and environments on potted poinsettia performance have become better understood over the past few decades. Light levels are often quite low in postproduction environments: generally brightest in supermarkets, lower in home improvement stores, and often even lower in homes away from windows. Postproduction, low light stress leading to leaf, bract, and cyathia abscission has long been studied (Embry and Nothnagel, 1994; Nell and Barrett, 1986; Shanks et al., 1970). Low temperatures are not a major issue for poinsettias in the retail environment because the optimum temperature for them is similar to that needed to keep people comfortable, but low temperatures can negatively impact plants, so it is recommended that plants be stored and shipped between 13 and $16{ }^{\circ} \mathrm{C}$ (Nell et al., 1995). Care to maintain this temperature range throughout supply chain handling is particularly important in northern climates where short-term exposure to suboptimal temperatures during transport is a real threat. The impact of sleeving is often considered in conjunction with light and/or temperature because it can influence potted poinsettia postharvest quality retention (Scott et al., 1983 ) by restricting air movement, inducing endogenous ethylene production, and lowering the level of light reaching the foliage. Insufficient substrate moisture can be a major problem for postproduction plants because irrigation frequency is typically suboptimal, with plants sometimes receiving no water after the last irrigation before packing for shipment, and low water stress is known to lead to leaf yellowing and abscission (Islam and Joyce, 2015).

Selecting cultivars that are tolerant of postharvest conditions is recommended (Islam and Joyce, 2015) based on studies that have shown that cultivars can differ greatly in durability to environmental stressors (Embry and Nothnagel, 1994; Miller and

\begin{tabular}{llll}
\hline $\begin{array}{l}\text { Units } \\
\begin{array}{l}\text { To convert U.S. to SI, } \\
\text { multiply by }\end{array}\end{array}$ & U.S. unit & SI unit & $\begin{array}{l}\text { To convert SI to U.S., } \\
\text { multiply by }\end{array}$ \\
\hline 10.7639 & $\mathrm{fc}$ & $\mathrm{lx}$ & 0.0929 \\
29.5735 & $\mathrm{fl} \mathrm{oz}$ & $\mathrm{mL}$ & 0.0338 \\
2.54 & inch $(\mathrm{es})$ & $\mathrm{cm}$ & 0.3937 \\
16.3871 & inch & $\mathrm{cm}^{3}$ & 0.0610 \\
1.1983 & $\mathrm{lb} / 100 \mathrm{gal}$ & $\mathrm{g} \cdot \mathrm{L}^{-1}$ & 0.8345 \\
0.0749 & $\mathrm{oz} / 100 \mathrm{gal}$ & $\mathrm{g} \cdot \mathrm{L}^{-1}$ & 13.3526 \\
1 & $\mathrm{Ppm}$ & $\mathrm{mg} \cdot \mathrm{L}^{-1}$ & 1 \\
$\left({ }^{\circ} \mathrm{F}-32\right) \div 1.8$ & ${ }^{\circ} \mathrm{F}$ & ${ }^{\circ} \mathrm{C}$ & $\left({ }^{\circ} \mathrm{C} \times 1.8\right)+32$
\end{tabular}


Heins, 1986; Nell et al., 1997). Fourteen to 20 modern poinsettia cultivars were grown under current standard production practices to determine responses to three environmental stressors to which postproduction poinsettia plants are commonly exposed: low light levels, low temperatures, and low substrate moisture.

\section{Materials and methods}

Three experiments with postharvest poinsettia plants were conducted in 2014 (year 1) and 2015 (year 2) at the Horticulture Field Laboratory in Raleigh, NC. The low light levels experiment was conducted in year 1 only, and the low temperatures and low substrate moisture experiments were conducted in years 1 and 2 .

Plant production PROTOCOL. Production methods were the same for plants in all experiments and in both years. Rooted cuttings were received from commercial growers and potted at the end of the first week of August. Cuttings were planted singly into green, plastic, azalea, $6 \frac{1}{2}-\times 45 /$ 8 -inch (volume, 105 inch $^{3}$ ) pots (The $\mathrm{HC}$ Companies, Middlefield, $\mathrm{OH}$ ) containing peat-based, soilless substrate (Fafard P4; Conrad Fafard, Agawam, MA) and were placed into a glass glazed greenhouse on 4 Aug. in year 1 and 6 Aug. in year 2 with set day/night temperatures of $75 / 64^{\circ} \mathrm{F}$ under natural daylength. Plants were pinched to two nodes above the substrate line on 27 Aug. in year 1 and 26 Aug. in year 2. Set day/night temperatures were lowered to $60 / 70{ }^{\circ} \mathrm{F}$ at the end of the second week of November. No plant growth regulators were used. The location of Raleigh, NC (lat. $35.8^{\circ} \mathrm{N}$ ) and the absence of light pollution at the field laboratory allow timely flower and bract development without use of black cloth.

Routine plant management in both years included constant liquid feed fertilizer, maintenance of substrate $\mathrm{pH}$ between 5.8 and 6.2 , and occasional fungicide applications. Daily fertilizer was applied at 250 ppm N, alternating between $20 \mathrm{~N}-$ $4.4 \mathrm{P}-16.6 \mathrm{~K}$ and $15 \mathrm{~N}-0 \mathrm{P}-12.5 \mathrm{~K}$ (JR Peters, Allentown, PA). Sodium molybdate at 0.1 ppm was included in both daily fertilizers. Drenches of $1 \mathrm{lb} / 100 \mathrm{gal}$ magnesium sulfate were applied in mid September and mid October. A soluble trace element mix at $4 \mathrm{oz} / 100 \mathrm{gal}$ was applied on 1 and 22 Oct. Proper pH was maintained through testing substrate leachate (HI9810-6 pH/EC meter; Hanna Instruments, Woonsocket, RI) using the PourThru extraction method (Cavins et al., 2000) and switching between nitrate-based and ammoniumbased fertilizers if necessary. Drenches of fludioxonil at $0.5 \mathrm{oz} / 100 \mathrm{gal}$ (Medallion $^{\circledR}$; Syngenta Crop Protection, Greensboro, NC) were applied during the first week of September and the first week of October. No unusual pests or diseases were noted in plants for any experiment.

Plants were grown in the greenhouse until anthesis, at which point they were placed into postharvest experiments. Visible pollen on two flowers was considered anthesis for a single plant, but plants of a given cultivar were not placed into a postharvest experiment until all plants required for that cultivar in an experiment had at least two flowers showing pollen.

YeAR 1 CULTIVARs. The first-year experiments included 14 poinsettia cultivars (followed by anthesis date in parentheses): Christmas Day Red (21 Nov.), Cortez Burgundy (26 Nov.), Early Mars Red (2l Nov.), Neva (5 Dec.), Orion Red (14 Nov.), Premium Red (14 Nov.), Prestige Early Red (14 Nov.), Prestige Red (21 Nov.), Sigma (14 Nov.), Sonora White Glitter (26 Nov.), Titan Pink (14 Nov.), Titan Red (14 Nov.), Titan White (14 Nov.), and Whitestar (21 Nov.). All 14 cultivars were in all three year 1 experiments, and the average date for anthesis in year 1 was 19 Nov.

Year 2 cultivars. The second year included 20 poinsettia cultivars (followed by anthesis date in parentheses): Christmas Beauty Red (23 Nov.), Christmas Day Red (23 Nov.), Cortez Burgundy (23 Nov.), Early Mars Red (18 Nov.), Magma Red (25 Nov.), Mars Pink (18 Nov.), Mars White (18 Nov.), Neva (30 Nov.), Orion Red (11 Nov.), Premium Red (23 Nov.), Prestige Early Red (18 Nov.), Prestige Red (21 Nov.), Protégé Dark Red (23 Nov.), Sigma (16 Nov.), Sonora White Glitter (25 Nov.), Titan Pink (6 Nov.), Titan Red (6 Nov.), Titan White (6 Nov.), Venus Hot Pink (25 Nov.), and Whitestar (23 Nov.). All 20 cultivars were in the year 2 low temperatures experiment, and all but three
(Christmas Beauty Red, Christmas Day Red, and Orion Red) were in the year 2 low substrate moisture experiment. The average date for anthesis in year 2 was 19 Nov.

EXPT. 1: Low Light LEVELS EXPERIMENT (YEAR 1). Nine similar plants per cultivar were selected at anthesis, irrigated, allowed to drain for $1 \mathrm{~h}$, cleaned of yellow leaves, and placed into translucent, satin sleeves (Hummert International, Earth City, MO). Sleeves were high-density polyethylene with eight vent holes on each of four sides and had a base diameter of 8 inches, a top diameter of 24 inches, and height of 30 inches. Sleeved plants were then placed in low light similar to a retail sales rack (10 $\mu \mathrm{mol} \cdot \mathrm{m}^{-2} \cdot \mathrm{s}^{-1}$ for $12 \mathrm{~h} \cdot \mathrm{d}^{-1}$ ) at a constant temperature of $20{ }^{\circ} \mathrm{C}$ for $2 \mathrm{~d}$, during which time they were not irrigated. All plants were unsleeved after $2 \mathrm{~d}$, and three plants per cultivar were subjected to each of three lightlevel treatments for $12 \mathrm{~h} \cdot \mathrm{d}^{-1}$ : low ( 10 $\left.\mu \mathrm{mol} \cdot \mathrm{m}^{-2} \cdot \mathrm{s}^{-1}\right)$, comparable to a location within a home away from windows; medium (20 $\left.\mu \mathrm{mol} \cdot \mathrm{m}^{-2} \cdot \mathrm{s}^{-1}\right)$, comparable to a home improvement store; and high $\left(40 \mu \mathrm{mol} \cdot \mathrm{m}^{-2} \cdot \mathrm{s}^{-1}\right)$, comparable to a supermarket. Different light levels were imposed by adjusting multiple layers of shade cloth and measuring photosynthetic active radiation $(P A R)$ with a handheld light meter (MQ-500; Apogee Instruments, Logan, UT) at the top of plant canopies at noon on a cloudfree day. Average daylength during the 7 weeks of the experiment was $10 \mathrm{~h}$ 50 min. This experiment was conducted in a greenhouse with set day/ night temperatures of $16 / 21^{\circ} \mathrm{C}$, and plants were watered as needed with tap water.

EXPT. 2: LOW TEMPERATURES EXPERIMENT (YEARS 1 AND 2). Twelve similar plants per cultivar were selected at anthesis, irrigated, allowed to drain for $1 \mathrm{~h}$, cleaned of yellow leaves, and placed into the same type of sleeve as described for Expt. 1. Three plants per cultivar were subjected to one of four temperature/ duration treatments during which they remained sleeved: $2 \mathrm{~d}$ at $20{ }^{\circ} \mathrm{C}$, $2 \mathrm{~d}$ at $5{ }^{\circ} \mathrm{C}, 10 \mathrm{~d}$ at $5{ }^{\circ} \mathrm{C}$, and $2 \mathrm{~d}$ at $2{ }^{\circ} \mathrm{C}$. A fifth temperature/duration treatment, $10 \mathrm{~d}$ sleeved at $20^{\circ} \mathrm{C}$, was included in year 2 only. Whether in the $20^{\circ} \mathrm{C}$ postharvest laboratory or 5 and $2{ }^{\circ} \mathrm{C}$ walk-in coolers, the light 
level during the temperature/duration treatments was $10 \mu \mathrm{mol} \cdot \mathrm{m}^{-2} \cdot \mathrm{s}^{-1}$ [PAR measured with a hand-held light meter (MQ-500) at the top of plant canopies] for $12 \mathrm{~h} \cdot \mathrm{d}^{-1}$ provided by fluorescent bulbs, and accuracy of thermostatic controls was verified by thermometers placed with plants during treatments. Plants were not irrigated while sleeved. At the end of temperature/duration treatments, plants were unsleeved and placed on tabletops in a postharvest laboratory that approximates environmental conditions in an average home: constant temperature of $20^{\circ} \mathrm{C}, 20 \mu \mathrm{mol} \cdot \mathrm{m}^{-2} \cdot \mathrm{s}^{-1}$ light for $12 \mathrm{~h} \cdot \mathrm{d}^{-1}$, and $40 \%$ to $60 \%$ relative humidity.

Expt. 3: Low SUBStrate MOISTURE EXPERIMENT (YEARS 1 AND 2). Fifteen similar plants per cultivar were selected at anthesis, irrigated, allowed to drain for $\mathrm{l} \mathrm{h}$, and cleaned of yellow leaves. Six plants were placed immediately onto tables in a postharvest laboratory, of which three were never irrigated and three were irrigated as needed throughout the experiment. The other nine plants were placed into the same type of sleeve as described for Expt. 1 and placed in low light similar to a retail sales rack $\left(10 \mu \mathrm{mol} \cdot \mathrm{m}^{-2} \cdot \mathrm{s}^{-1}\right.$ for 12 $\mathrm{h} \cdot \mathrm{d}^{-1}$ ) at a constant temperature of $20^{\circ} \mathrm{C}$, where they remained without irrigation for $10 \mathrm{~d}$. After the $10-\mathrm{d}$, insleeve treatment, these plants were unsleeved and placed onto tables in the postharvest laboratory. Three of the nine were left unirrigated at unsleeving and for the remainder of the experiment to simulate a retail environment with no plant care, three were irrigated one time with $150 \mathrm{~mL}$ tap water at unsleeving only to simulate a retail environment with moderate plant care, and three were irrigated at unsleeving and as needed thereafter. Plants in this last treatment were irrigated when noticeably light when picked up to simulate care in a plantloving consumer's home. Each irrigation was with $150 \mathrm{~mL}$ tap watera volume that moistened the substrate well but did not drain from the pot. Only the three treatments following holding sleeved plants for $10 \mathrm{~d}$ without irrigation were included in year 2 .

Data collection. Data were recorded $3 \mathrm{~d}$ per week (Monday, Wednesday, and Friday) for the first 2 weeks after treated plants were placed into observation environments (some of which were additional treatments) and then once per week through 7 weeks for the low lightlevels experiment and through 5 weeks for the low temperatures and low substrate moisture experiments. Data included days to first abscised flower, first yellow leaf, first abscised leaf, and first abscised bract, and days to most/all flower buds having abscised or turned brown. Number of abscised leaves was recorded at the end of each week. Days to a plant having an unacceptable appearance, as judged by pronounced wilting or dropping of leaves and/or bracts, was recorded, if it occurred before the end of an experiment. The same data were recorded by the same evaluator during year 2 .

EXPERIMENT DESIGN AND DATA ANALYSES. Within each experiment, once a cultivar had a sufficient number of uniform plants at anthesis to impose all treatments, those plants were assigned randomly to treatments. In every case there were three individual plants per cultivar-bytreatment combination. After imposition of treatments, plants were placed in random order in the postharvest laboratory. Each experiment was conducted as a randomized complete block design, with three blocks and one plant for every cultivar-bytreatment combination in each block. The low temperatures and low substrate moisture experiments from year $\mathrm{l}$ were replicated in a second year. Thus, year was included as an additional variable in the statistical analyses for the two experiments with just the 14 (temperature) or 12 (low substrate moisture) cultivars in common over the 2 years.

Statistical analyses were conducted with JMP Pro (version 13.2.1; SAS Institute, Cary, NC). For continuous, dependent variables, a standard least squares method was used to perform analyses of variance that included all main effects and all one-way interactions. For binary dependent variables, ordinal logistic fit models were used, and the standard Pearson chi-square statistic was used to determine significance of the effects of independent variables and their interactions. Means separations were determined in all cases using Tukey's honest significant difference test for pairwise means comparisons with a significance level of $\alpha=0.05$.

\section{Results and discussion}

LOW LIGHT LEVELS. Light level influenced poinsettia postharvest performance, but appeared of limited commercial importance, even when plants were held beyond the original 5 -week experiment to 7 weeks. Compared with the average for plants in the medium and low light treatments, plants in the high light treatment retained all bracts $9 \mathrm{~d}$ longer and kept an acceptable appearance $3 \mathrm{~d}$ longer (Table 1). A contingency analysis of the frequency of plants within each light level treatment with acceptable appearance after 7 weeks showed this difference more dramatically, with $95 \%, 74 \%$, and $71 \%$ of plants with acceptable appearance under the high, medium, and low light treatments, respectively (Pearson's chisquare test, $P=0.0020)$. However, the commercial importance of this is questionable because this difference was not observed at 6 weeks or earlier.

Influence of light level on number of days to most/all flower buds having abscised or turned brown (data not shown) was similar to that seen for days to first flower abscission (Table 1). Likewise, influence of light level on cumulative number of abscised leaves through 6 weeks (data not shown) and through 7 weeks (data not shown) was similar to that for the number of leaves abscised by the end of 5 weeks (Table 1 ). The data analysis for cumulative leaf abscission at 5 weeks is shown because that is the last week in which all plants remained in the experiment.

Differences among cultivars were observed for every trait, and lack of block as a significant source of variation indicated that plant performance among the three blocks was uniform (Table 1). When the experiment was ended at 7 weeks, all plants for six of the 14 cultivars were considered of acceptable appearance under all light level treatments (Christmas Day Red, Early Mars Red, Neva, Prestige Red, Titan White, Whitestar). Four cultivars had more than 33\% unacceptable plants across light level treatments at 7 weeks (Cortez Burgundy, Orion Red, Premium Red, Prestige Early Red), and four cultivars were intermediate with just one or two plants considered unacceptable at 7 weeks (Sonora White Glitter, Titan Pink, Sigma, Titan Red). That cultivars 
Table 1. Postharvest response of 14 poinsettia cultivars to low light levels (Expt. 1). ${ }^{\mathrm{z}}$

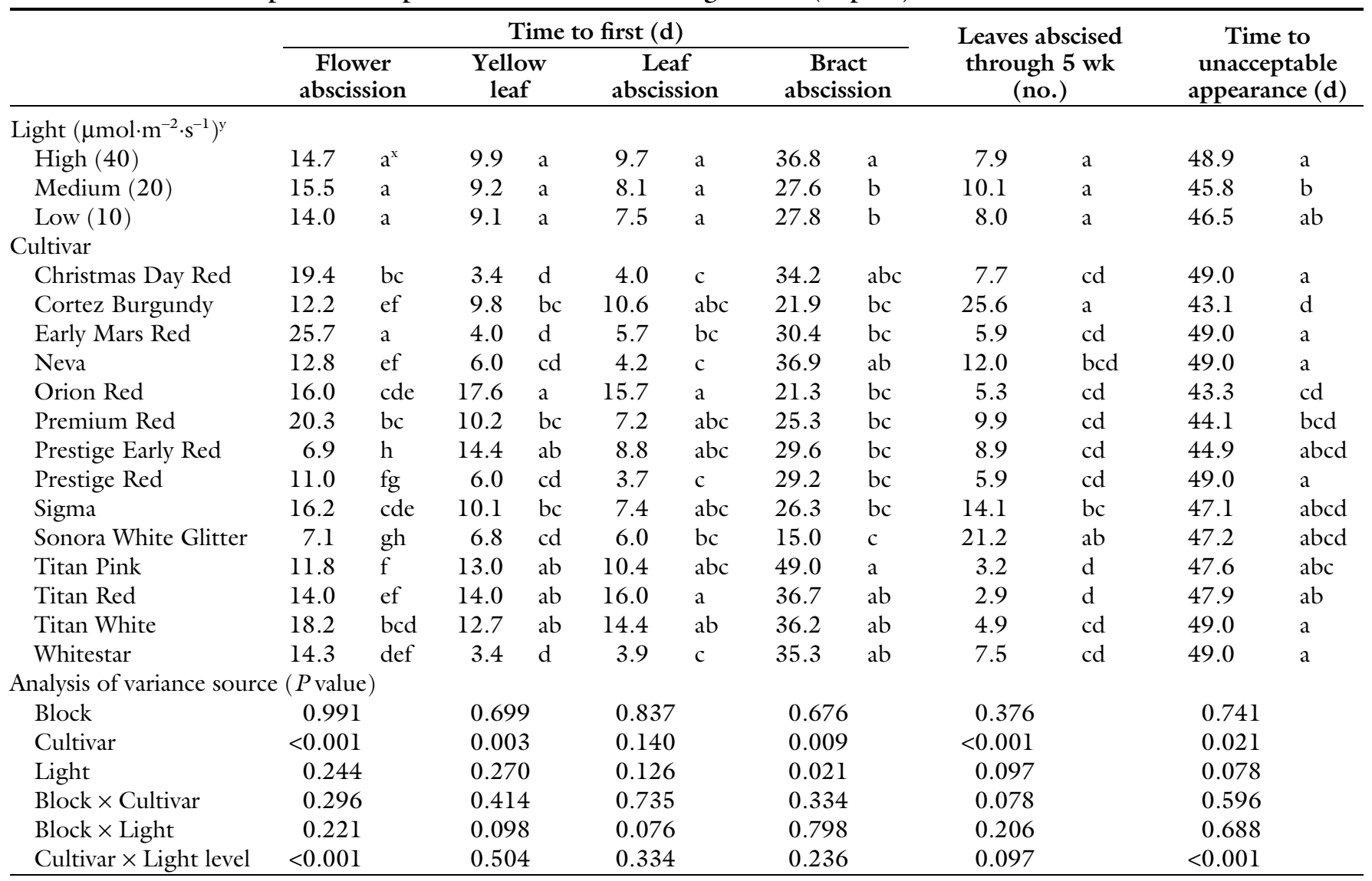

${ }^{z}$ Plants were placed under three low-light levels for $11 \mathrm{~h} \cdot \mathrm{d}^{-1}$, and are comparable to a consumer's home $\left(\right.$ low, $\left.10 \mu \mathrm{mol} \cdot \mathrm{m}^{-2} \cdot \mathrm{s}^{-1}\right)$, a retail home improvement store $(\mathrm{medium}$, $20 \mu \mathrm{mol} \cdot \mathrm{m}^{-2} \cdot \mathrm{s}^{-1}$ ), or a supermarket (high, $40 \mu \mathrm{mol} \cdot \mathrm{m}^{-2} \cdot \mathrm{s}^{-1}$ ). Plants were held in a greenhouse with set temperatures of $16 / 21{ }^{\circ} \mathrm{C}$ day $/$ night, with shade cloth providing the different light levels, and plants were watered as needed with tap water. There was one plant per each light level by cultivar combination in each of three complete blocks, and plants were observed for 7 weeks.

${ }^{\mathrm{y}} 1 \mu \mathrm{mol} \cdot \mathrm{m}^{-2} \cdot \mathrm{s}^{-1}$ sunlight $=5.01 \mathrm{fc}=53.927 \mathrm{~lx} ;\left(1.8 \times{ }^{\circ} \mathrm{C}\right)+32={ }^{\circ} \mathrm{F}$.

${ }^{x}$ Values within a column and independent variable not followed by the same letter are significantly different at $\alpha=0.05$ according to Tukey's honest significant difference test.

differed in response to light-level treatments was also reflected in the significant $(P<0.001)$ interaction between cultivar and light level for days to unacceptable appearance, because the first group of six cultivars showed no differences among the light-level treatments (i.e., $49 \mathrm{~d}$ to unacceptable appearance for all levels), and the other eight cultivars responded by having fewer numbers of days to unacceptable appearance for the low and/or medium light-level treatments. Considering all traits, five cultivars were identified as relatively tolerant of low postharvest light levels: Christmas Day Red, Early Mars Red, Prestige Red, Titan White, and Whitestar.

Low TEMPERATURes. Analyses using data from the 14 cultivars and four temperature/duration treatments tested in both years 1 and 2 showed that exposing plants to $5{ }^{\circ} \mathrm{C}$ for $10 \mathrm{~d}$ had a significant negative effect on postharvest performance of potted poinsettias. The negative impact was not readily apparent early in the experiment because days to first flower abscission, yellow leaf, and leaf abscission did not differ significantly between a 10 - $\mathrm{d}$ exposure to $5^{\circ} \mathrm{C}$ and a 2 -d exposure to 2,5 , or $20^{\circ} \mathrm{C}$, but total number of abscised leaves through 3 weeks was greater and number of days to unacceptable appearance was reduced from 34 to $20 \mathrm{~d}$ when comparing the 10-d exposure to the 2-d exposure at any temperature (Table 2). Exposing plants to 2 or $5{ }^{\circ} \mathrm{C}$ for $2 \mathrm{~d}$ did not impact plant postharvest performance compared with $20{ }^{\circ} \mathrm{C}$ for $2 \mathrm{~d}$ for any dependent variable, with the exception of total number of leaves abscised through 3 weeks (Table 2). For that variable, the $2{ }^{\circ} \mathrm{C}$-for- $2 \mathrm{~d}$ treatment resulted in more abscised leaves than the 5 and $20^{\circ} \mathrm{C}$-for- $2 \mathrm{~d}$ treatments, which did not differ from each other (Table 2). The data indicate that these modern poinsettias are quite tolerant of short-duration low temperatures.

Significant differences among cultivars were observed for every dependent variable (Table 2). Years differed for early traits, with plants in year 1 having earlier first flower abscission, yellow leaf, leaf abscission, and bract abscission, and more leaves abscised through 3 weeks compared with year 2 (Table 2 ). However, years did not differ for the later variables of number of days to unacceptable appearance and frequency of plants with unacceptable appearance at or before 5 weeks (Table 2 ). The interaction between cultivar and year was significant for almost all variables assessed, but statistically different responses between years within a cultivar were rare for all dependent variables, indicating that the many nonsignificant differences between years within cultivars resulted in the significant cultivarby-year interactions. Shifts in cultivar ranking between years were minor for 
Table 2. Postharvest response of 14 poinsettia cultivars to low temperatures (Expt. 2). ${ }^{\mathrm{z}}$

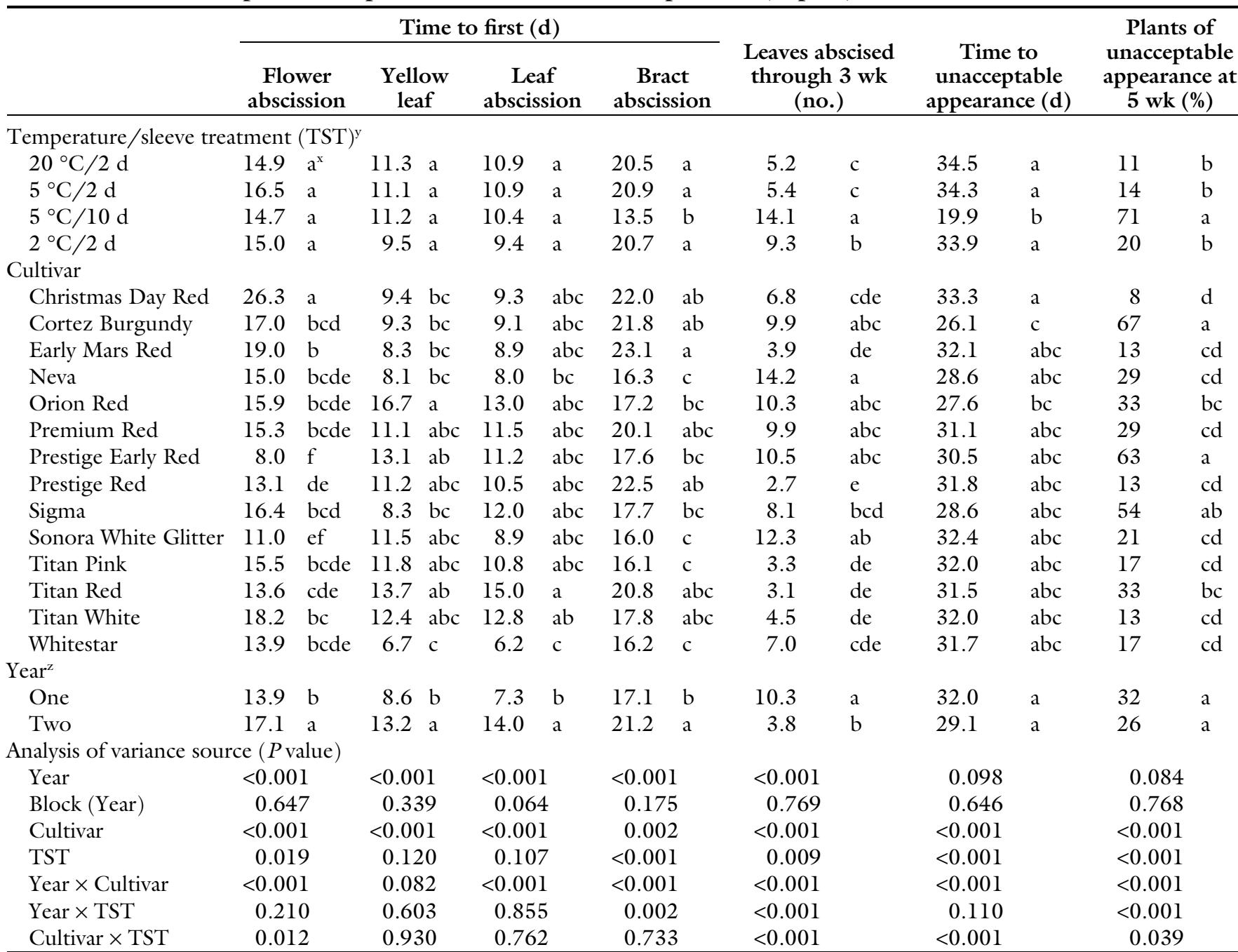

${ }^{\mathrm{z}}$ Plants were put into perforated polyethylene sleeves and held under $10 \mu \mathrm{mol} \cdot \mathrm{m}^{-2} \cdot \mathrm{s}^{-1}$ light for $12 \mathrm{~h} \cdot \mathrm{d}^{-1}$ for $2 \mathrm{~d}$ at 2,5 , or $20{ }^{\circ} \mathrm{C}$ or for $10 \mathrm{~d}$ at $5{ }^{\circ} \mathrm{C}$ then placed in a room at a constant temperature of $20^{\circ} \mathrm{C}, 20 \mu \mathrm{mol} \cdot \mathrm{m}^{-2} \cdot \mathrm{s}^{-1}$ light for $12 \mathrm{~h} \cdot \mathrm{d}^{-1}$, and $40 \%$ to $60 \%$ relative humidity. There was one plant per each temperature/sleeve treatment by cultivar combination in each of three blocks, plants were observed for 5 weeks, and the experiment was conducted in years 1 and 2 .

${ }^{\mathrm{y}} 1 \mu \mathrm{mol} \cdot \mathrm{m}^{-2} \cdot \mathrm{s}^{-1} \mathrm{cool}$ white fluorescent $=6.87 \mathrm{fc}=73.948 \mathrm{~lx} ;\left(1.8 \times{ }^{\circ} \mathrm{C}\right)+32={ }^{\circ} \mathrm{F}$.

${ }^{\mathrm{x}}$ Values within a column and independent variable not followed by the same letter are significantly different at $\alpha=0.05$ according to Tukey's honest significant difference test.

all dependent variables, with a couple exceptions. For example, two of the 14 cultivars had significantly $(P<0.01)$ different number of days to unacceptable appearance between years, but one had greater longevity in year 1 ( 35 vs. $29 \mathrm{~d}$ for 'Prestige Red') and the other in year 2 ( $25 \mathrm{vs}$. $32 \mathrm{~d}$ for 'Orion Red').

Some cultivars were less tolerant than others of exposure to $5^{\circ} \mathrm{C}$ for $10 \mathrm{~d}$. For example, $100 \%$ of 'Cortez Burgundy', 'Neva', and 'Sigma' plants in that treatment were ended early for cold injury - a frequency that was significantly greater (Pearson's chi-square test, $P<0.0001)$ than for other cultivars, all of which were less than $50 \%$ and were not different from each other. Considering all traits, five of the 14 cultivars represented in both years appeared to be relatively tolerant when exposed to low temperatures as might occur during normal shipping and handling of poinsettias: Christmas Day Red, Early Mars Red, Prestige Red, Titan Red, and Titan White.

When all 20 cultivars were compared in year 2 , exposing plants to $5{ }^{\circ} \mathrm{C}$ for $10 \mathrm{~d}$ had significant negative effects on postharvest performance of potted poinsettias that were apparent within 2 weeks in terms of days to first bract abscission and days to unacceptable appearance, and later in the experiment in terms of number of leaves abscised through 3 weeks and frequency of plants of unacceptable appearance at 5 weeks (Table 3). Comparing responses of plants exposed to $20{ }^{\circ} \mathrm{C}$ for $10 \mathrm{~d}$ to those exposed for $2 \mathrm{~d}$ showed minimal effects of the longer time in sleeve and at low light, with only number of leaves abscised through 3 weeks being negatively affected by the longer exposure (Table 3). Low temperature had a much more pronounced negative impact than time in sleeves on postharvest poinsettias, as seen in comparing plants exposed for $10 \mathrm{~d}$ at $5{ }^{\circ} \mathrm{C}$ to those exposed for $10 \mathrm{~d}$ at $20{ }^{\circ} \mathrm{C}$, with days to first bract abscission, number of leaves abscised through 3 weeks, number of days to unacceptable appearance, and frequency of plants of unacceptable appearance at 5 weeks being negatively impacted by the lower temperature (Table 3).

Differences among cultivars were observed for all dependent variables except number of days to unacceptable 


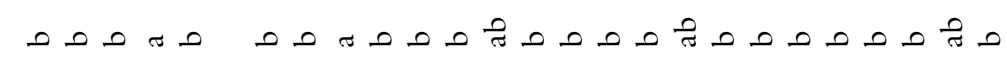

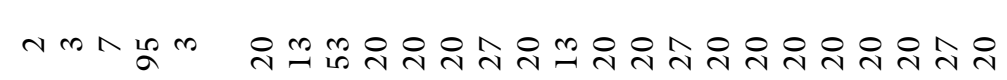

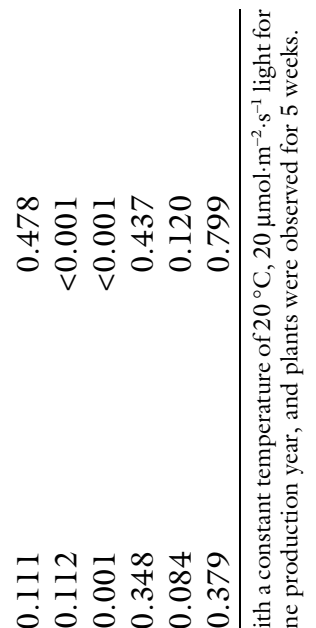

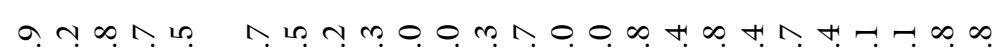

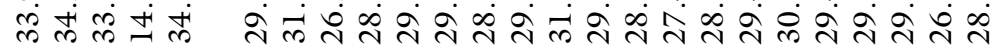

ט ט ט

के

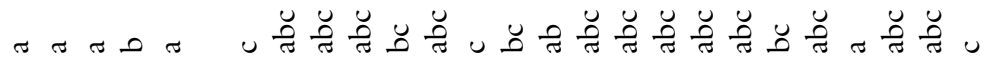

क人

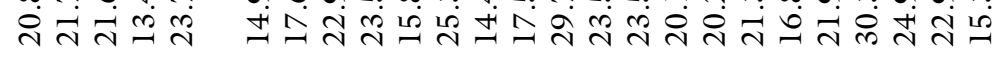

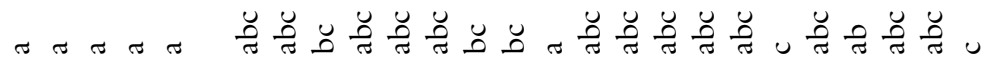

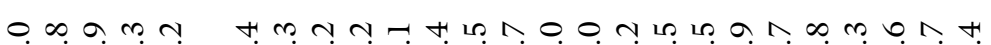

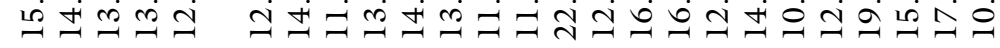

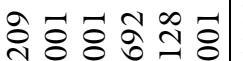

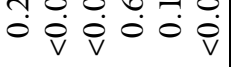

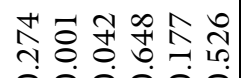

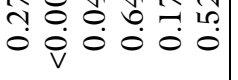

कूे

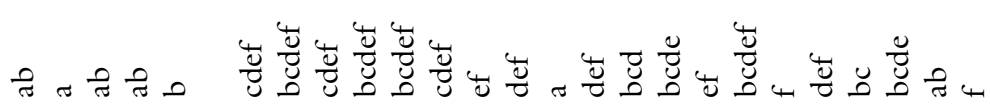

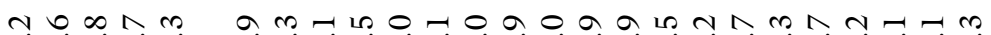
サே்

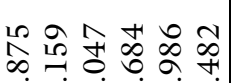

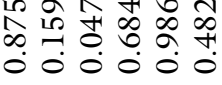

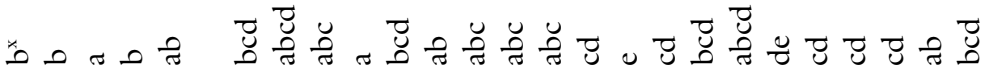
育

$\bigoplus \infty \wedge 0.9$ 눙

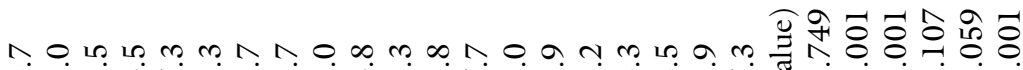

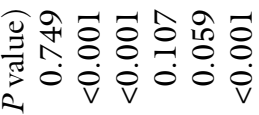

에

$\overline{\mathscr{U}}$

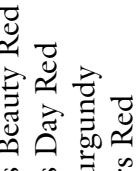

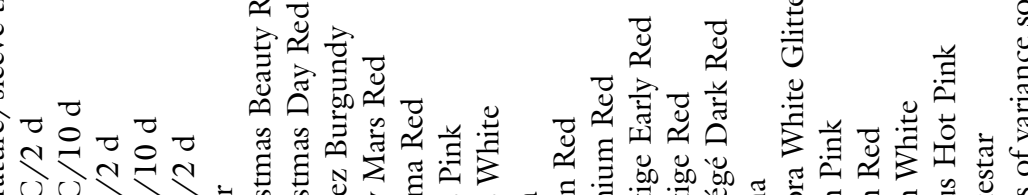

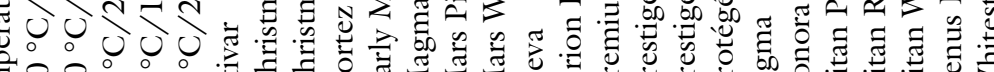

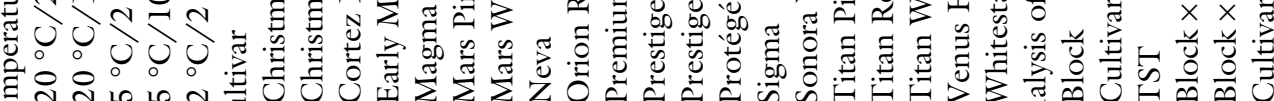
总 
appearance (Table 3 ). Of the six cultivars tested in only 1 year, Venus Hot Pink showed promise based on the high number of days to first flower abscission, yellow leaf, leaf abscission, and bract abscission, and low number of leaves abscised through 3 weeks (Table 3). 'Venus Hot Pink' performed similarly to the five cultivars found to be low-temperature tolerant across 2 years, except that its number of days to first flower abscission was greater than three of the five cultivars (Table 3). 'Orion Red' was unusual in that it was a cultivar that was among the best performers according to analyses using the 20 cultivars in year 2 only (Table 3 ), but it was not according to analyses using the 14 cultivars and treatments common to both years (Table 2).

Low Substrate moisture. Cultivar and sleeve/irrigation treatment influenced postharvest performance of potted poinsettias in year 1 according to all dependent variables (Table 4). Influence of sleeve/irrigation treatment on number of days to most/all flower buds having abscised or turned brown (data not shown) was similar to that seen for days to first flower abscission (Table 4). The sleeve/irrigation treatment influence on cumulative number of abscised leaves through 4 weeks (data not shown) and through 5 weeks (data not shown) was similar to that seen for the number of leaves that had abscised by the end of 3 weeks (Table 4 ). The data analysis for cumulative leaf abscission at 3 weeks is shown because that is the last week in which nearly all plants remained in the experiment.

In year 1 , sleeving plants and placing them under low light for the first $10 \mathrm{~d}$ rarely impacted postharvest plant performance variables when compared with not sleeving the plants. The one exception was that plants that were never irrigated were of an acceptable appearance for $5 \mathrm{~d}$ longer if they were sleeved compared with those that were not sleeved (Table 4).

Cultivar response to low substrate moisture in year $\mathrm{l}$ varied greatly. For example, 'Christmas Day Red' plants across treatments had four abscised leaves through 3 weeks and $0 \%$ plants of unacceptable appearance in less than 4 weeks, whereas 'Neva' plants had five times the number of abscised leaves and $60 \%$ plants of unacceptable appearance during the same time periods. Five of the 14 cultivars in year 1 appeared to be relatively tolerant when exposed to low substrate moisture based on having a high number of days to first bract abscission and/or a low number of leaves abscised through 3 weeks and a high number of days to unacceptable appearance: Christmas Day Red, Early Mars Red, Premium Red, Sigma, and Whitestar.

Data for year 2 were first analyzed on their own because the two nonsleeved treatments were not included in year 2 based on year 1 observations, and only 12 of the 17 cultivars in year 2 were represented in year 1 . Cultivar and sleeve/irrigation treatment influenced postharvest performance (Table 5). Irrigating plants once at unsleeving or as needed did not influence days to first flower abscission or leaf abscission or number of leaves abscised through 3 weeks (Table 5) and did not influence number of days to most/all flower buds having abscised or turned brown (data not shown), which was similar to that seen for days to first flower abscission. The sleeve/irrigation treatment influence on cumulative number of abscised leaves through 4 weeks (data not shown) and through 5 weeks (data not shown) was nonsignificant, as seen for the number of leaves that had abscised by the end of 3 weeks (Table 5 ). The data analysis cumulative leaf abscission at 3 weeks is shown because that is the last week in which nearly all plants remained in the experiment. Compared with nonirrigated plants, irrigating plants as needed slightly delayed first bract abscission and dramatically reduced frequency of plants of unacceptable appearance in less than 4 weeks (Table 5). A single irrigation at unsleeving increased number of days to unacceptable appearance by more than a week and reduced frequency of plants of unacceptable appearance in less than 4 weeks by nearly half compared with nonirrigated plants (Table 5).

Differences among cultivar responses were observed for all dependent variables in year 2 (Table 5), including number of days to most/ all flower buds having abscised or turned brown (data not shown) for which cultivars had nearly the same ranking as for days to first bud abscission but over a greater time spread, ranging from Early Prestige Red having all abscised flowers at 13 $\mathrm{d}$ to Early Mars Red not reaching that point until $30 \mathrm{~d}$. Seven of the 17 cultivars in year 2 appeared to be relatively tolerant when exposed to low substrate moisture based on having a high number of days to first bract abscission and/or a low number of leaves abscised through 3 weeks and a high number of days to unacceptable appearance: Early Mars Red, Premium Red, Prestige Early Red, Sigma, Titan Red, Titan White, and Whitestar.

Data for the cultivar (12)-bysleeve/irrigation treatment (3) combinations (36) common to years 1 and 2 were combined for a statistical analysis including year as an independent variable. Year and cultivar influenced all dependent variables, and sleeve/irrigation treatment influenced the later dependent variables only (Table 6). Plants performed better across cultivars and treatments in year 2 as measured by all dependent variables, and the interaction between cultivar and year was significant for all dependent variables (Table 6). Statistically different responses between years within a cultivar were rare for all dependent variables, indicating that many small and nonsignificant differences between years within cultivars resulted in the significant cultivar-byyear interactions. Shifts in cultivar ranking between years were minor for all variables, with a couple exceptions. For example, although nine of 12 cultivars were statistically the same in both years, as measured by number of days to unacceptable appearance, three cultivars had significantly $(P<0.01)$ greater longevity in year 2 (19 vs. $31 \mathrm{~d}$ for Neva, 22 vs. $35 \mathrm{~d}$ for Prestige Early Red, and 24 vs. $36 \mathrm{~d}$ for Titan Red). Thus, as found in the low temperatures experiment, the significant difference between years and the significant interaction between year and cultivar for all dependent variables indicate the importance of conducting experiments such as these over more than 1 year.

Six of the 12 cultivars evaluated in both years were relatively tolerant of low substrate moisture based on having a high number of days to first bract abscission and/or a low number of leaves abscised through 3 weeks and a greater number of days to unacceptable appearance: Early Mars 


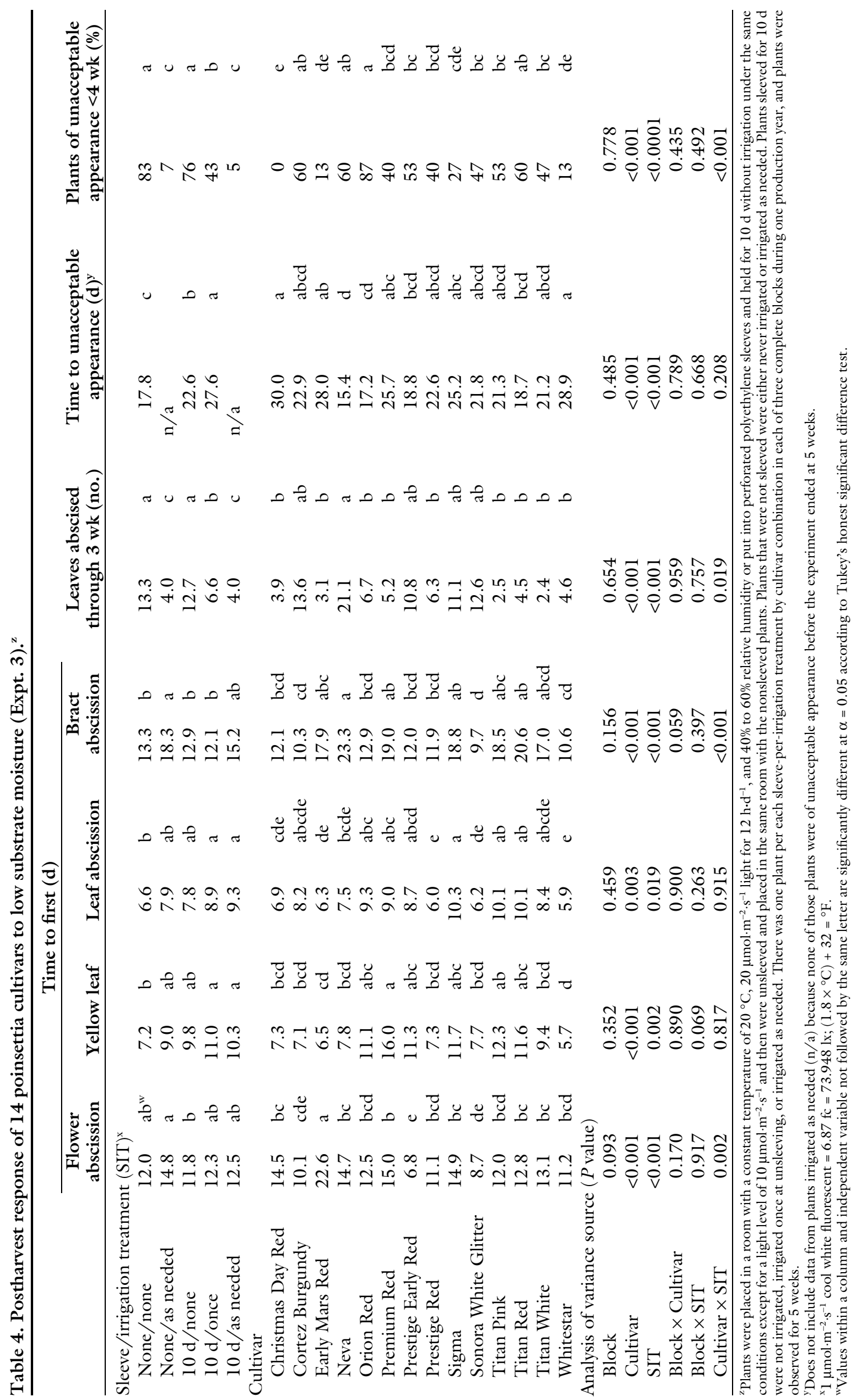




\section{Research Reports}

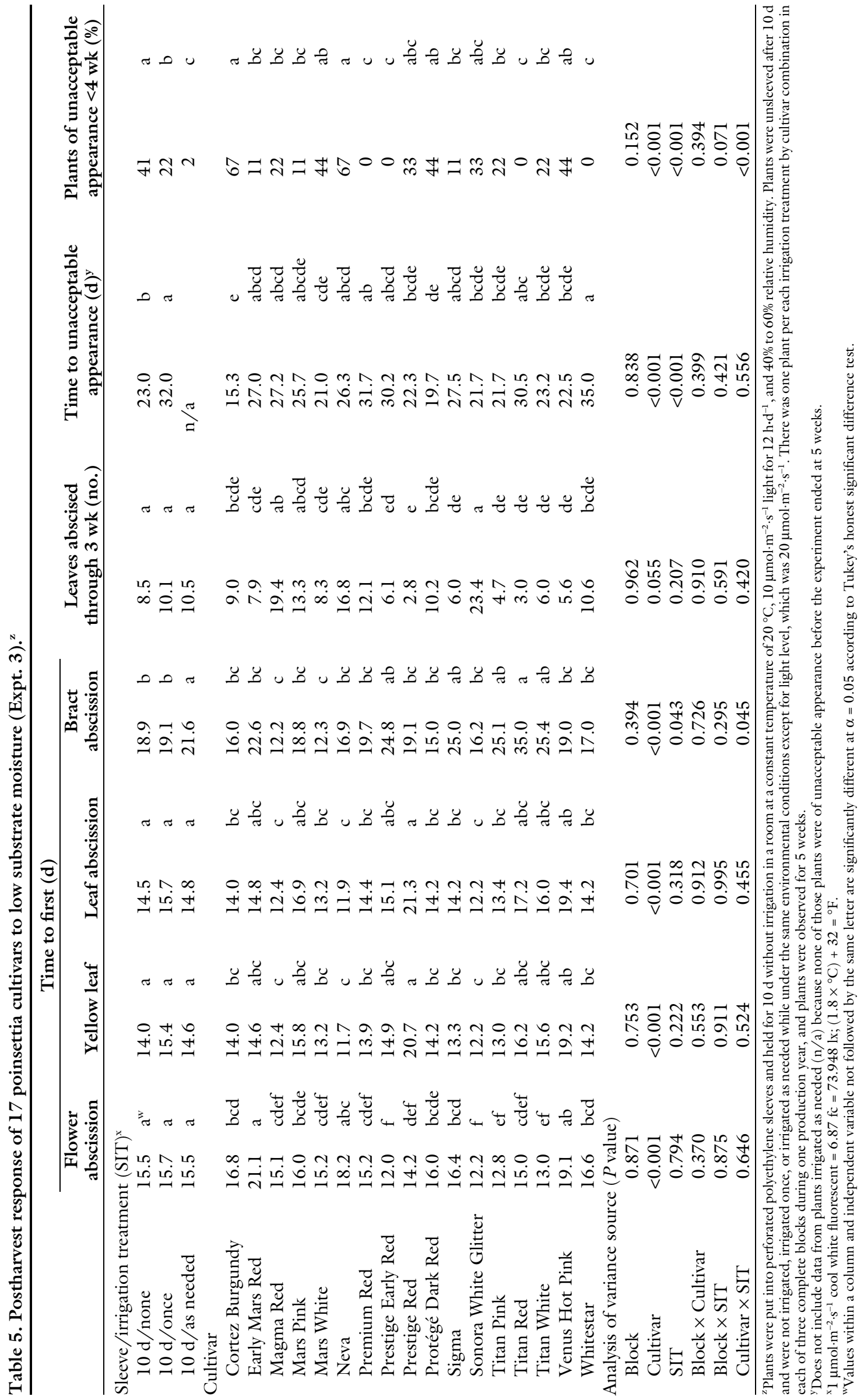




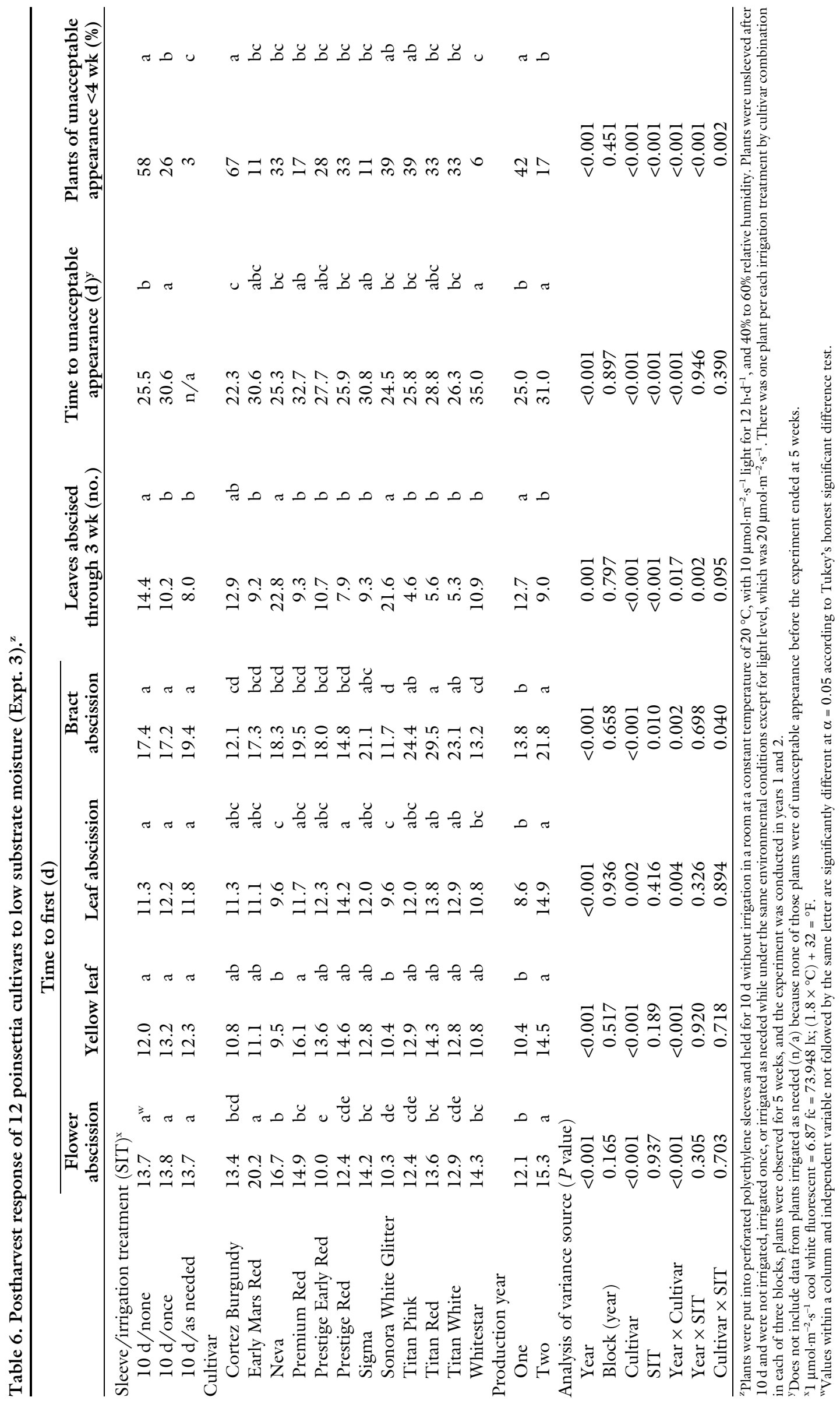


Red, Premium Red, Prestige Early Red, Sigma, Titan Red, and Whitestar. Four of these ('Early Mars Red', 'Premium Red', 'Sigma', and 'Whitestar') were considered among the most tolerant cultivars in both years, and two ('Prestige Early Red' and 'Titan Red') were identified as such in only 1 of the 2 years.

Separate experiments were conducted to determine responses of modern poinsettia cultivars to low light levels, low temperatures, and low substrate moisture because they are conditions to which postproduction poinsettia plants are commonly exposed. The considerable tolerances observed in many cultivars to each of the environmental stressors reflect the efforts made over recent decades within breeding programs to improve postharvest potted poinsettia performance, but poinsettias still often look poor in retail environments. Among the possible explanations for this discrepancy are 1) stressors were imposed separately in this work, and plants in the retail environment likely experience combinations of stressors; 2) suboptimal temperatures and irrigation were tested, but significant postharvest life reductions can be caused by overly warm (Tijskens et al., 1996) and overly wet [e.g., by promoting root rot (Benson et al., 2002)] conditions, which may also occur during postharvest handling; and 3 ) there are factors not tested in this work that are known to be postharvest challenges for poinsettias, such as mechanical damage (Leonard et al., 1994), exposure to ethylene (Islam and Joyce, 2015), and use of plastic rather than paper sleeves (Staby et al., 1978). The customary use of handcarts at many large retailers illustrates several of these points. Densely packing plasticsleeved plants onto carts can result in mechanical damage, subsequent ethylene production from injured tissues (Michell, 1977; Sacalis, 1977), and severely reduced light levels, particularly for interior plants on the cart. Leaving plants nonirrigated on a cart for extended periods can result in heat and/or ethylene buildup within the sleeves (Sacalis, 1977) and low water stress. Poor cart placement-for example, in direct sun or on hot pavement-even for a short period can be very detrimental to the plants.

\section{Conclusions}

Many of the 20 poinsettia cultivars tested proved to be highly tolerant of low light levels and/or low temperatures and/or low substrate moistures. These stressors are common in the postharvest supply chain and in the environments provided by final consumers. Three cultivars were shown to be relatively tolerant of all three sources of plant stress: Christmas Day Red (not tested in year 2 in the low substrate-moisture experiment), Early Mars Red, and Titan White (superior in year 2 only in the low substrate-moisture experiment). Three cultivars appeared to be relatively tolerant in two of the three experiments: Prestige Red (low light levels and low temperatures), Titan Red (low temperatures and low substrate moisture), and Whitestar (low light levels and low substrate moisture). Average number of days to unacceptable appearance across these six cultivars was more than 49,32 , and $31 \mathrm{~d}$ across light-level, temperature, and substrate-moisture treatments, respectively. This indicates that if these cultivars were to comprise a grower's crop and were exposed to a typical range of favorable and adverse postharvest conditions, it could be expected that plants would maintain a satisfactory postharvest appearance for longer than 1 month.

\section{Literature cited}

Bailey, D.A. and W.B. Miller. 1991. Poinsettia development and postproduction responses to growth retardants and irradiance. HortScience 26:1501-1503.

Benson, D.M., J.L. Hall, G.W. Moorman, M.L. Daughtrey, A.R. Chase, and K.H. Lamour. 2002. The history and diseases of poinsettia, the Christmas flower. 2 June 2017. <http://plantmanagementnetwork. org/pub/php/review/xmasflower/>.

Cavins, T.J., B.E Whipker, W.C. Fonteno, B. Harden, I. McCall, and J.L. Gibson. 2000. Monitoring and managing $\mathrm{pH}$ and EC using the PourThru extraction method. North Carolina State Univ. Hort. Info. Lflt. 590.

Dunn, B.L., C. Goad, and S. Stanphill. 2011. Performance of 40 poinsettia cultivars grown under two different temperatures. J. Hort. For. 3:72-77.

Embry, J.L. and E.A. Nothnagel. 1994. Leaf senescence of postproduction poin- settias in low-light stress. J. Amer. Soc. Hort. Sci. 119:1006-1013.

Islam, M.A. and D.C. Joyce. 2015. Postharvest behavior and keeping quality of potted poinsettia: A review. Res. Agr. Livestock Fisheries 2:185-196.

Islam, M.A., G. Kuwar, J.L. Clarke, D.-R. Blystad, H.R. Gislerød, J.E. Olsen, and S. Torre. 2012. Artificial light provided by light emitting diodes (LEDs) with a high portion of blue light results in more compact poinsettia compared to the traditional high pressure sodium (HPS) lamps. Scientia Hort. 147:136-143.

Jackson, B.E., R.D. Wright, and M.C. Barnes. 2008. Pine tree substrate, nitrogen rate, particle size, and peat amendment affect poinsettia growth and substrate physical properties. HortScience 43:21552161.

Leonard, R.T., T.A. Nell, and J. Barrett. 1994. Deliver poinsettias the consumer will enjoy. Flori-Report Fall:4-5.

Michell, C.A. 1977. Influence of mechanical stress on auxin-stimulated growth of excised pea stem sections. Physiol. Plant. 41:129-134.

Miller, S.H. and R.D. Heins. 1986. Variation in cyathia abscission of poinsettia cultivars in a greenhouse and a simulated postharvest environment. HortScience 21:270-272.

Moe, R., T. Fjeld, and L.M. Mortensen. 1992. Stem elongation and keeping quality in poinsettia (Euphorbia pulcherrima Willd. ex Klotzsch) as affected by temperature and supplementary lighting. Scientia Hort. 50:127-136.

Nell, T.A. and J.E. Barrett. 1986. Growth and incidence of bract necrosis in 'Gutbier V-14 Glory’ poinsettia. J. Amer. Soc. Hort. Sci. 111:266-269.

Nell, T.A., J.E. Barrett, and R.T. Leonard. 1997. Production factors affecting postproduction quality of flowering potted plants. HortScience 32:817-819.

Nell, T.A., R.T. Leonard, and J.E. Barrett. 1995. Production factors affect the postproduction performance of poinsettia: A review. Acta Hort. 405:132-137.

Roude, N., T.A. Nell, and J.E. Barrett. 1991. Nitrogen source and concentration, growing medium, and cultivar affect longevity of potted chrysanthemums. HortScience 26:49-52.

Sacalis, J. 1977. Epinasty and ethylene evolution in petioles of sleeved poinsettia plants. HortScience 12:388.

Scott, L.F., T. Blessington, and J. Price. 1983. Postharvest effects of temperature, dark storage duration, and sleeving on 
quality retention of 'Gutbier V-14 Glory' poinsettia. HortScience 18:749-750.

Shanks, J.B., W.E. Noble, and W.T. White. 1970. Influence of light and temperature upon leaf and bract abscission in poinsettia. J. Amer. Soc. Hort. Sci. 95:446-449.

Staby, G.L. and A.M. Kofranek. 1979. Production conditions as they affect harvest and postharvest characteristics of poinsettias. J. Amer. Soc. Hort. Sci. 104:88-92.
Staby, G.L., J.F. Thompson, and A.M. Kofranek. 1978. Postharvest characteristics of poinsettias as influenced by handling and storage procedures. J. Amer. Soc. Hort. Sci. 103:712-715.

Stromme, E., A.R. Selmer-Olsen, H.R. Gislerød, and R. Moe. 1994. Cultivar differences in nutrient absorption and susceptibility to bract necrosis in poinsettia (Euphorbia pulcherrima Willd. ex Klotzsch). Gartenbauwissenschaft 59:612. ter Hell, B. and L. Hendricks. 1995. The influence of nitrogen nutrition on keeping quality of pot plants. Acta Hort. 405:138147.

Tijskens, L.M.M., M. Sloof, E.C. Wilkinson, and W.G. van Doorn. 1996. A model of the effects of temperature and time on the acceptability of potted plants stored in darkness. Postharvest Biol. Technol. 8:293-305. 